\title{
Systematic review of evidence and consensus on diverticulitis: an analysis of national and international guidelines
}

\author{
S. Vennix*†, D. G. Morton‡, D. Hahnloser§, J. F. Lange† and W. A. Bemelman* on behalf \\ of the research committee of the European Society of Coloproctocology
}

*Department of Surgery, Academic Medical Center, Amsterdam, The Netherlands, †Department of Surgery, Erasmus MC University Medical Centre, Rotterdam, The Netherlands, łAcademic Department of Surgery, University of Birmingham, Birmingham, UK and §Department of Visceral Surgery, University Hospital CHUV, Lausanne, Switzerland

Received 16 December 2013; accepted 7 February 2014; Accepted Article online 7 May 2014

\begin{abstract}
Aim The study aimed to analyse the currently available national and international guidelines for areas of consensus and contrasting recommendations in the treatment of diverticulitis and thereby to design questions for future research.

Method MEDLINE, EMBASE and PubMed were systematically searched for guidelines on diverticular disease and diverticulitis. Inclusion was confined to papers in English and those $<10$ years old. The included topics were classified as consensus or controversy between guidelines, and the highest level of evidence was scored as sufficient (Oxford Centre of Evidence-Based Medicine Level of Evidence of 3a or higher) or insufficient.
\end{abstract}

Results Six guidelines were included and all topics with recommendations were compared. Overall, in 13 topics consensus was reached and 10 topics were regarded as controversial. In five topics, consensus was reached without sufficient evidence and in three topics there was no evidence and no consensus. Clinical staging, the need for intraluminal imaging, dietary restriction, duration of antibiotic treatment, the protocol for abscess treatment, the need for elective surgery in subgroups of patients, the need for surgery after abscess treatment and the level of the proximal resection margin all lack consensus or evidence.

Conclusion Evidence on the diagnosis and treatment of diverticular disease and diverticulitis ranged from nonexistent to strong, regardless of consensus. The most relevant research questions were identified and proposed as topics for future research.

Keywords Diverticulitis, diverticular disease, guideline, review, consensus

\section{Introduction}

Diverticular disease of the sigmoid colon is common, particularly in Caucasian populations. The prevalence increases with age and with exposure to certain lifestyle factors, such as a low-fibre diet and lack of physical exercise [2]. About $25 \%$ of patients with left colonic diverticulosis develop one or more episodes of symptomatic diverticulitis [3]. The inflammation of the diverticulum can progress to free perforation with peritonitis, abscesses, obstruction or fistula. Over recent decades, the treatment of diverticulitis has changed. Percutaneous drainage, antibiotic treatment and expectant policies lower the need for acute and elective surgical treatment.

Correspondence to: Prof. Dr. W. A. Bemelman, Department of Surgery, Academic Medical Center, Postbox 22660, II00 DD Amsterdam, The Netherlands.

E-mail: w.a.bemelman@amc.uva.nl
Currently, several national and international guidelines are available on the diagnosis and treatment of diverticulitis. Within these guidelines, several topics remain controversial, and even in the case of consensus, evidence is frequently lacking.

For this paper, a search of national and international guidelines on diverticulitis was performed. From the included guidelines the main topics of consensus and controversy were subtracted and the controversial topics were used to design new hypotheses for future research.

\section{Method}

A systematic search for guidelines on diverticular disease was performed. MEDLINE, EMBASE and PubMed were searched on 26 June 2013, and references and gastrointestinal and surgical society websites were searched for additional literature (Appendix S1). 
The inclusion criteria used were national and international guidelines, clear recommendations based on levels of evidence (LE) or grades of recommendation, a publication date within the past 10 years and the availability of a full-text version in English. If recommendations were not given in the format of the Oxford Centre of Evidence-Based Medicine Levels of Evidence (2009), we manually reassigned the levels of evidence as shown in Table S1 [1]. All topics discussed in the guidelines and followed by recommendations were included in this review. After analysing the recommendations, they were summarized and assessed for consensus or controversy. Consensus was defined as a topic discussed by at least two guidelines with a unanimous recommendation. For each topic, the highest level of evidence available was classified as sufficient (minimum LE of $3 \mathrm{a}$ ) or insufficient. All topics of interest for future research were debated in a plenary session during the European Society of Coloproctology (ESCP) 8th annual meeting in Belgrade and were listed according to relevance.

\section{Results}

\section{Search}

After searching EMBASE, MEDLINE and PubMed, 475 hits could be retrieved. After removal of duplicates and evaluation of the title and abstract, 256 relevant papers were identified. Careful evaluation of the abstract and full text resulted in 21 possible guidelines for further analysis. Hand searching resulted in three additional references (Fig. 1).

\section{Excluded guidelines}

Nineteen guidelines were considered for inclusion after excluding five previous versions of updated guidelines [4-8]. The Dutch NHG (Dutch Association of General Practitioners), French, Italian, Mexican and Spanish guidelines could not be retrieved in full text or the English language and were therefore excluded [9-13]. The Guidelines of the American College of Gastroenterology (ACG) and the Society of American Gastrointestinal and Endoscopic Surgeons (SAGES) were excluded because they were published more than 10 years ago $[14,15]$. No other guidelines contained recommendations and levels of evidence [16-27].

\section{Included guidelines}

The included guidelines were those of the American Society of Colon and Rectal Surgeons (ASCRS) 2006 [28], the Association of Coloproctology of Great

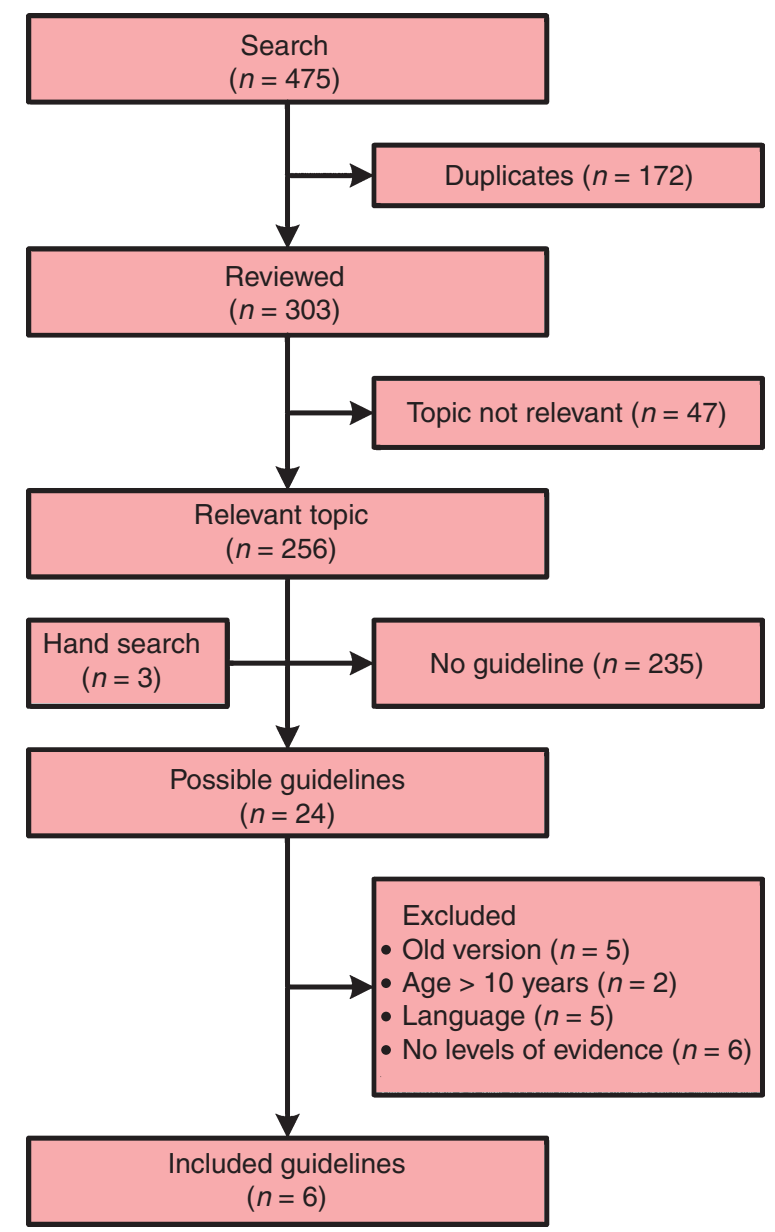

Figure I Flow chart showing the inclusion and exclusion criteria for the publications on diverticulitis included in this study.

Britain and Ireland (ACPGBI) 2011 [29], the Association of Surgeons of The Netherlands (ASN) $2012[30,31]$, the Danish Surgical Society (DSS) 2011 [32], the European Association for Endoscopic Surgery (EAES) 2011 [33] and the World Society for Emergency Surgery (WSES) 2013 (Table S2) [34].

The EAES and the WSES guidelines focus on the emergency surgical treatment of abdominal emergencies, including diverticulitis. The ASN guideline is published as an extensive document in Dutch, and has been summarized in English by Andeweg et al. [30]. The comparative findings from the reviewed guidelines are summarized in Table S3.

\section{Clinical diagnosis and staging}

\section{Staging of diverticular disease}

Various, but similar, classifications were used to describe diverticular disease in the included guidelines.

Acute diverticulitis was divided into complicated diverticulitis and uncomplicated diverticulitis by all but 
the WSES guideline. Complicated diverticulitis was defined as acute inflamed diverticula causing abscess formation, perforation or fistula, or late stenosis following recurrent disease. Diverticular hemorrhage was defined within complicated diverticulitis only by the ACPCBI. Uncomplicated diverticulitis was defined as inflammation and wall thickening without any abscess, perforation, fistula or bleeding.

The severity of acute complicated diverticulitis was classified according to the Hinchey [35] or modified Hinchey [36,37] classification, by all included guidelines. In addition, the DSS and the ASN also discuss the classification by Kaiser et al. [38], Ambrosetti et al. [39] and Hansen and Stock [40], although they recommend the use of the (modified) Hinchey classification because it is widely used in the literature. An overview of all classifications is presented in Table S4.

Conclusion: A uniform clinical and radiological classification for diverticulitis is lacking. Controversy, LE 5.

\section{Clinical diagnosis}

All guidelines recommend radiological evidence to support the diagnosis of diverticulitis. The ASN and the DSS describe three additional criteria with a high positive predictive value: abdominal pain in the left lower quadrant; a C-reactive protein (CRP) value of $<50 \mathrm{mg} / \mathrm{l}$; and the absence of vomiting. However, they do acknowledge the limited utility of these criteria, as they are met in only $25 \%$ of patients.

Conclusion: Clinical assessment alone for the diagnosis of diverticulitis is insufficiently precise. Consensus, LE 2a [41-44].

\section{Imaging for acute diverticulitis}

The WSES and the EAES guidelines do not discuss imaging modalities for acute diverticulitis. The others agree on a high accuracy of CT for the diagnosis of acute diverticulitis. The ACPGBI guideline does not provide a preference for the use of either CT or ultrasound (US) as both show equally high sensitivity and specificity, and recommends that the decision should be based on local expertise and availability. The ASN guideline advised the use of ultrasound, but when the outcome is negative or inconclusive, CT should be performed. An immediate CT scan is recommended for severe peritonitis because it is able to differentiate the possible causes more clearly. Except for pregnant and fertile women, the DSS guidelines recommend CT over ultrasound because it is less operator-dependent. The ASCRS does not discuss ultrasound as an alternative to CT.

The DSS states colonoscopy to be safe in acute diverticulitis without free air and recommends early colonoscopy when a sigmoid carcinoma is suspected. Other guidelines recommend delayed colonoscopy to reduce the risk of perforation. An interval of 6 weeks is considered to be safe, although evidence for this interval is lacking.

Conclusion: CT is accurate for the diagnosis of acute diverticulitis. Consensus, LE Ib $[39,45,46]$.

Both ultrasound and CT can be used to diagnose acute diverticulitis. Controversy, LE 1a $[42,47,48]$.

There is no role for colonoscopy in the acute phase to diagnose diverticulitis. Controversy, LE $2 b[49,50]$.

Routine intraluminal investigation after CT-diagnosed diverticulitis to exclude malignancy

Four guidelines recommend a routine colonoscopy after CT-diagnosed acute diverticulitis. The EAES and the ASCRS guidelines recommend routine colonoscopy without discussion. The ASN recommends limiting the indication to symptomatic patients only. The DSS agrees on the low additional risk of carcinoma in asymptomatic patients, but recommends routine colonoscopy anyway.

Conclusion: Routine intraluminal imaging following CT-diagnosed diverticulitis is recommended in symptomatic patients. Consensus, LE 2b $[39,51,52]$.

It is unclear if routine intraluminal imaging is required for asymptomatic patients following CT-diagnosed diverticulitis. Controversy, LE 2b [39,51,52].

\section{Risk factors}

Risk factors for the development of diverticular disease and complicated diverticulitis

Only the DSS and the ASN guidelines discuss risk factors for diverticular disease. Both report low dietary fibre and low physical activity to increase the risk, although the ASN does not give a clear recommendation on fibre intake. The evidence for the impact of obesity is inconsistent. Smoking is a risk factor for complicated disease, but not for the aetiology of diverticular disease. The ASN discusses additional risk factors, including nonsteroidal anti-inflammatory drugs (NSAIDs), renal failure, organ transplantation and steroid use for the development of complicated diverticulitis. Patients with human immunodeficiency virus (HIV), diabetes, malignancy or chemotherapy do not have an increased risk of complicated diverticulitis.

Conclusion: A low-fibre diet and lack of physical activity are risk factors for the development of diverticular disease. Consensus, LE 2b [53-55].

Smoking, NSAID use, renal failure, organ transplants and steroid use are risk factors for the development of complicated diverticulitis. Consensus, LE 2a [56]. 


\section{Treatment of uncomplicated diverticulitis}

Treatment of symptomatic and recurrent diverticular disease

No clear treatment protocol for symptomatic diverticular disease without acute inflammation is discussed in any of the guidelines. The ASN and the DSS recommend supplementary dietary fibre and it is suggested that cyclic rifaximin gives relief to one in three patients with persistent symptoms. If conservative therapy fails, three out of four patients will benefit from elective resection. In addition, the ASN suggests 5-aminosalicylic acid (5-ASA) and probiotics as treatment options. All have been reported to reduce the risk of recurrent disease.

Conclusion: Dietary fibre supplementation and rifaximin reduce symptoms and can reduce the risk of recurrent diverticular disease. Consensus, LE la [57-62].

\section{Outpatient treatment of acute uncomplicated} diverticulitis

The WSES and the ASCRS guidelines recommend outpatient treatment for mild cases of acute uncomplicated diverticulitis. They restrict this policy to those patients without fever and without excessive vomiting, who are able to take oral liquids, have no marked peritonitis and have a sufficient domestic support system and follow up. A recent randomized trial showed no difference in the outcome between hospitalization and outpatient treatment for Hinchey la diverticulitis [63].

Conclusion: Outpatient treatment is safe for mild cases of acute uncomplicated diverticulitis. Consensus, LE $1 b[63]$.

Routine antibiotics for acute uncomplicated diverticulitis The ASCRS, the EAES and the WSES recommend antibiotic treatment for acute uncomplicated diverticulitis, but the WSES acknowledges recent controversy in the need for antibiotics. Based on the same evidence, the DSS and the ASN guidelines do not recommend the routine use of antibiotics. They only recommend antibiotic treatment in pregnant patients, in patients with septicaemia or a poor general condition, or in patients who are receiving immunosuppressive therapy. When antibiotics are indicated, the ASCRS and the WSES recommend the use of intravenous antibiotics if patients are hospitalized and the ASN guidelines state that oral antibiotics are as effective. The length of the antibiotic course is discussed only in the ASN guideline, with 4 days being as effective as a 7 -day course of intravenous antibiotics.

Conclusion: There is no indication for the routine use of antibiotics in uncomplicated diverticulitis. Controversy, LE Ib $[8,64,65]$.
There is no indication for the preference of intravenous antibiotics over oral antibiotics. Controversy, LE lb $[8,65,66]$.

Dietary restriction in acute uncomplicated diverticulitis No evidence exists for the benefit of a restrictive diet in acute uncomplicated diverticulitis. The ASN and DSS guidelines recommend normal oral intake if tolerated in the acute phase. The ASCRS does not make a recommendation regarding diet but describes the option of dietary modification and the need to take oral liquids.

Conclusion: There is no evidence for dietary restriction in acute uncomplicated diverticulitis. Controversy, LE 5.

\section{Analgesia in acute uncomplicated diverticulitis}

The ASN guideline discussed the possible adverse effects of analgesia in diverticulitis. No evidence was reported for negative effects of acetaminophen, NSAIDs or morphine on the clinical course of acute diverticulitis. In chronic users, NSAIDs are associated with ulceration, perforation and bleeding of the intestine, but there is no evidence for a higher risk of complications from acute diverticular disease. The ASN guideline recommends stopping chronic NSAID use in patients with acute diverticulitis. The DSS guidelines also describe a higher risk of diverticular bleeding with use of NSAIDs and acetaminophen in diverticular disease but do not discuss the effect in acute diverticulitis.

Conclusion: It is unclear whether NSAIDs and acetaminophen should be avoided in the treatment of acute diverticulitis. Controversy, LE 5.

\section{Treatment of complicated diverticulitis}

Acute treatment of mesocolic and pelvic abscesses

All guidelines recommend conservative management of small mesocolic abscesses with antibiotics and recommend percutaneous drainage for larger abscesses. The definition of a large abscess was one that ranged in size from $>2$ to $>5 \mathrm{~cm}$. No consideration is given to the option of percutaneous aspiration only, including the duration of drainage. No evidence is available on drainage without antibiotics.

Conclusion: Small abscesses can be treated with antibiotics, and for large abscesses percutaneous drainage and antibiotics are recommended. Consensus, LE $2 \mathrm{~b}$ [67-69].

Pelvic abscesses require more aggressive therapy compared with mesocolic abscesses, with percutaneous drainage and elective surgery if unsuccessful. Consensus, LE $2 b[39,70,71]$.

There is no evidence for a preferred drainage regime. Controversy, LE 5. 


\section{Laparoscopic lavage for Hinchey III perforated diverticulitis}

All but ASCRS discuss the option of laparoscopic lavage for Hinchey III diverticulitis. They state that it is a safe approach for selected patients with Hinchey III diverticulitis. The ASN guideline only advises lavage within a clinical trial setting. No clear recommendations were given regarding lavage as a bridge to elective resection or as a final treatment option.

Conclusion: Laparoscopic lavage is safe for selected patients with Hinchey III diverticulitis. Consensus, LE 3a $[72-78]$.

Primary anastomosis for Hinchey III-IV perforated diverticulitis

Most guidelines recommend a sigmoid resection if a perforation is seen. Only the EAES suggest the option of suturing the perforation and application of an omental patch if no faecal contamination is present. The WSES guideline recommends Hartmann's procedure for all patients with generalized peritonitis. The ASN recommends primary anastomosis over Hartmann's procedure for haemodynamically stable patients. Others recommend resection without a clear preference for primary anastomosis or Hartmann's procedure.

Conclusion: Primary anastomosis is safe for haemodynamically stable patients with Hinchey III and Hinchey IV diverticulitis. Controversy, LE 2b [79-81].

Laparoscopic resection for Hinchey III-IV perforated diverticulitis

Only the EAES and the ASN guidelines discuss the option for a laparoscopic approach in haemodynamically stable patients. Others do not specify recommendations on acute or elective resections for complicated diverticulitis.

Conclusion: Acute laparoscopic resection is safe for haemodynamically stable patients with perforated diverticulitis. Consensus, LE 4 [79-81].

\section{Elective treatment of diverticulitis}

Elective surgery following acute uncomplicated diverticulitis

All but one guideline recommends an individualized treatment rather than routine elective resection. The presence of persistent symptoms, the frequency and severity of attacks and the low risk of complicated recurrence do not justify elective resection after any number of episodes. Recruitment is currently underway for a randomized trial in which elective surgery will be compared with conservative treatment [82].
Conclusion: There is no routine indication for elective surgery following uncomplicated diverticulitis. Consensus, LE 2a [83-85].

\section{Elective surgery in young patients}

Of all patients hospitalized for diverticulitis, only 20$30 \%$ are under 50 years of age. The longer life expectancy of younger patients is associated with a slightly higher lifetime risk of complications and recurrence. The ACPGBI, the ASN and the DSS do not recommend different indications for elective treatment based on age. The ASCRS recognizes that the risks are only increased as a result of the longer lifespan of such patients, but does not make a recommendation on whether or not this is an indication for elective treatment.

Conclusion: There is no additional indication for elective surgery based on an age under 50 years. Consensus, LE 3b [86-88].

\section{Elective surgery in immunocompromised patients}

The ASN and the DSS guidelines discuss the indications for elective surgery in immunocompromised patients. The DSS guideline justifies surgery after the first episode of diverticulitis in patients with immunosuppressive therapy, chronic renal failure and collagen-vascular disease, as they have an increased risk of perforation in recurrent episodes of diverticulitis. The ASN guideline advises against screening and prophylactic surgery. The controversy is based on the balance of risk from complicated diverticulitis and morbidity vs the risk of prophylactic sigmoid resection.

Conclusion: Earlier elective surgery might be justified because of an increased risk of complications in selected immunocompromised patients. Controversy, LE 2a $[56,89]$.

\section{Elective surgery after nonsurgical treatment of abscesses}

The ASCRS guideline recommends elective surgery for all patients following diverticular abscesses, but acknowledges the possibility of nonoperative management. The ACPGBI and the WSES only recommend elective surgical treatment for pelvic abscesses because of their poor long-term prognosis. The guidelines agree that successfully treated mesocolic abscesses do not routinely require surgery.

No recommendations related to the size of the abscess were made by any guideline.

Conclusion: There is no evidence for a routine indication for elective surgery after nonsurgical treatment of abscesses. Controversy, LE 4 [70,90,91].

Pelvic abscesses do have a higher recurrence rate and might justify surgery. Controversy, LE 2b [70]. 
Elective surgery in complicated diverticulitis with obstruction or fistula

The ASN, the DSS and the EAES guidelines recommend routine sigmoid resection for complicated diverticulitis with fistula or stenosis. However, the DSS guideline recommends individualized treatment in highrisk patients. Patients with a high surgical risk may benefit from colostomy without resection of the diseased segment.

Conclusion: Complicated diverticulitis with obstruction or fistula is an indication for elective surgery, although more conservative options are possible for high-risk patients. Consensus, LE 4 [92].

Oncological resection for suspected, but unconfirmed, malignancy

The ASCRS, the ASN and the DSS recommend oncological surgical resection if the imaging of the colon is suspect for malignancy because a differential diagnosis of diverticulitis and definitive diagnosis with colonoscopy is not possible.

Conclusion: Surgery is indicated when carcinoma cannot be excluded. Consensus, LE 5 .

\section{Level of resection for elective surgery}

The ACPGBI, the ASN and the DSS guidelines agree that the distal resection margin should be on the proximal rectum. For the proximal margin, all guidelines recommend not to resect all diverticulosis and to make an anastomosis in soft, compliant bowel tissue.

Conclusion: The distal resection margin should be on the proximal rectum and the proximal margin should be in soft compliant bowel. Consensus, LE 4 [93,94].

\section{Laparoscopic surgery for uncomplicated diverticulitis}

Laparoscopic surgery for elective resection in symptomatic and recurrent disease is recommended over open surgery by all included guidelines. Laparoscopy results in less morbidity and in faster recovery. The guidelines limit their recommendation to experienced laparoscopic surgeons and to elective surgery and advise caution in complicated disease.

Conclusion: Laparoscopic elective surgery for uncomplicated diverticulitis is preferred when surgery is indicated. Consensus, LE $1 \mathrm{~b}[95,96]$.

\section{Discussion}

\section{Quality of available guidelines}

The six included guidelines are all initiated or approved by national or international surgical societies. Figure 2 shows that there are more topics with consensus than without, but within both groups about the same proportion of topics have sufficient ( $\mathrm{LE} \geq 3 \mathrm{a}$ ) supporting evidence. In Table S3 an overview of the levels of evidence and of the best-supporting references is given for each topic and each guideline. Many topics were without consensus, or were with consensus but without sufficient supporting evidence. In two topics, consensus was achieved with sufficient evidence, but these were discussed in only two of the guidelines. These are discussed with the aim of forming new, clinically relevant, research questions.

\section{Topics without consensus}

\section{Staging}

Although all guidelines use the (modified) Hinchey classification, there is no consensus regarding the best classification system. None differentiate between small air pockets in the pericolic fat, a large air pocket around the sigmoid or a massive pneumoperitoneum. In a recent study evaluating CT images blinded for the Hinchey classification, over $50 \%$ of the patients with a surgical Hinchey I or II Stage had localized gas bubbles on CT [97]. Even though free air is strongly associated with perforated diverticulitis, it can overestimate the Hinchey classification. Costi et al. [98] showed that diverticulitis with limited pericolic air can be treated nonsurgically with antibiotics and percutaneous drainage only. This option is not addressed by any of the included guidelines.

\section{Imaging}

Despite the high levels of evidence, no consensus was reached concerning the preferred imaging modality for acute diverticulitis. There is sufficient evidence on the high sensitivity and specificity of both CT and ultrasound, but there is controversy about which is preferred. This is based on local preference and experience, as the quality of ultrasound depends on the experience of the sonographer. CT is more likely to distinguish between alternative diagnoses, but ultrasound is safer for fertile and pregnant women.

\section{Imaging following nonsurgically treated diverticulitis} After the first episode of acute diverticulitis, most guidelines recommend routine intraluminal imaging to exclude other possible diagnoses, such as carcinoma. However, data from cohort studies do not show an increased incidence of colorectal carcinoma in asymptomatic patients after CT-diagnosed uncomplicated diverticulitis $[99,100]$. Only the ASN does not recommend routine intraluminal imaging for CT-diagnosed asymptomatic patients based on these data. 
(a)

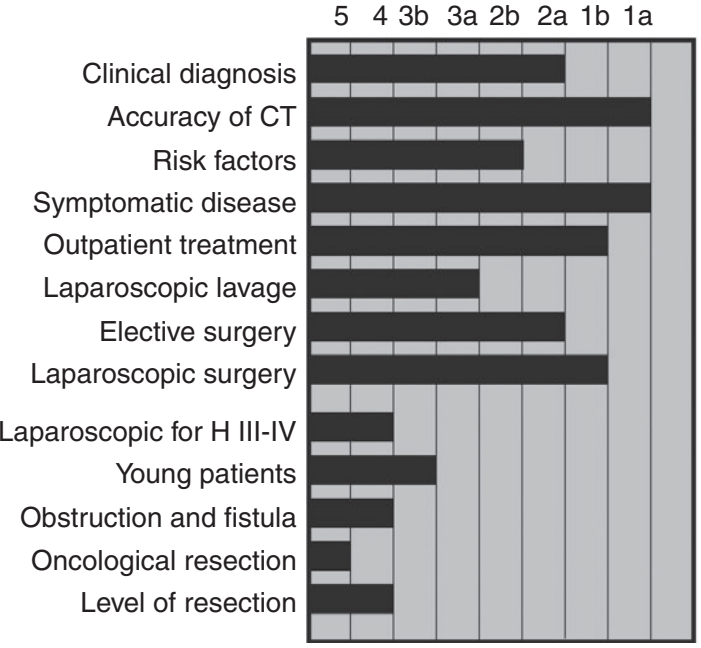

(b)

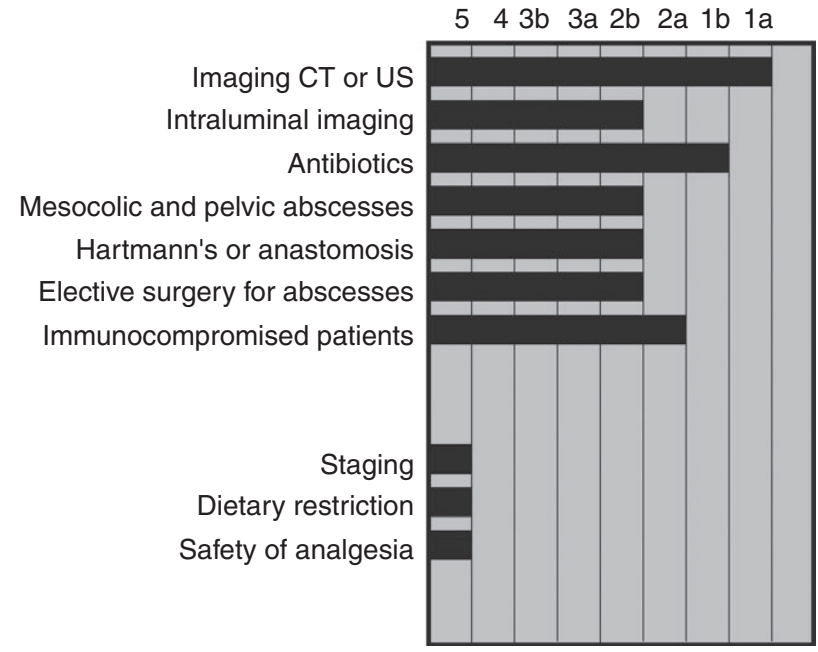

Figure 2 Summary of included topics. (a) Topics with consensus, highest level of evidence available. (b) Topics without consensus, highest level of evidence available. H III-IV, Hinchey III-IV diverticulitis; US, ultrasound.

\section{Dietary restrictions and medical therapy for acute diverticulitis}

Although dietary restriction is common practice for the treatment of acute diverticulitis, no guideline provides any fact-based evidence. Two guidelines do recommend a normal oral diet if tolerated and this has recently been supported by clinical data [101]. The use of NSAIDs and acetaminophen has been associated with an increased risk of diverticular bleeding and perforation in chronic users $[102,103]$. No evidence is available regarding the risk of NSAID use in the acute setting.

\section{Antibiotic treatment for acute uncomplicated diverticulitis}

Antibiotic treatment for acute uncomplicated diverticulitis is routinely used to prevent septic complications. Several studies reported no beneficial effect of the routine use of antibiotics [8]. The results of a second, large, recently completed randomized study are awaited to ascertain whether these provide more evidence for a change in recommendations [104].

\section{Surgical treatment for Hinchey III and IV perforated diverticulitis}

Open Hartmann's procedure has been the standard of care for perforated diverticulitis. Sigmoid resection with primary anastomosis has been introduced as an alternative for haemodynamically stable patients $[105,106]$. Whilst most guidelines recommend Hartmann's procedure or refrain from a recommendation, recent studies provide evidence of similar results with primary anastomosis. When stoma reversal is taken into account, primary anastomosis (with or without ileostomy) results in lower morbidity rates [106]. More evidence is awaited from the randomized controlled ladies trial [107].

Treatment of complicated diverticulitis with abscesses Consensus is reached for the nonsurgical treatment of abscesses with antibiotics and percutaneous drainage. The indications are clear, but a proper treatment protocol for duration of drainage and the need for subsequent sigmoid is missing. The cut-off size for the need of percutaneous drainage is unclear, as is the difference in therapy for mesocolic and pelvic abscess formation. Duration of drainage and flushing regimes are not even mentioned. Follow-up data show lower recurrence rates for mesocolic abscesses compared with pelvic abscesses after successful nonsurgical treatment. Whether these risks justify routine surgery or an expectant treatment policy remains unclear.

\section{Immunocompromised patients}

Earlier elective surgery might be justified in patients with immunosuppressive therapy, chronic renal failure and collagen-vascular disease. These patients are known to have a higher risk of diverticulitis and complications when diverticulosis is present. However, it remains unclear if the reduced complications as a result of earlier elective surgery outweigh the risks of elective surgery in these patients. More evidence would help to define the timing of surgical intervention. 


\section{Topics with consensus but lacking high-quality evidence}

Risk factors for the development of diverticular disease Low fibre intake has been reported as a risk factor for the development of diverticular disease, with sufficient evidence, but this is based on one study from 1998 [55]. Since then, several others have been published with contrasting conclusions, but have not been included in the guidelines [108,109].

\section{Need for oncologic resection and resection margins}

If a suspected malignancy cannot be excluded by colonoscopy, all guidelines recommend resection with oncological margins. No evidence is presented, but in this case Level 5 evidence is acceptable as a study would be unethical. The level of resection is agreed upon for the distal margin $[93,94]$. For the proximal margin, guidelines also agree on not to resect all diverticula without evidence to support this statement.

\section{Laparoscopic surgery for acute and elective treatment of diverticulitis}

Laparoscopic sigmoid resection for uncomplicated diverticulitis is the preferred treatment in experienced hands, but acute laparoscopic resection for perforated diverticulitis is less commonly undertaken. Only a few case series have been described and are the basis of weak recommendations by the DSS and the EAES. More clinical studies are required to establish the safety and feasibility of acute laparoscopic resection for perforated diverticulitis.

\section{Indications for elective surgery following complicated diverticulitis}

Surgical resection for the elective treatment of obstruction and fistula is recommended. For high-risk patients, conservative treatment, endoscopic stent insertion or a diverting stoma may result in an acceptable outcome [92].

\section{Elective surgery in young patients}

Younger patients have a similar absolute risk of recurrence, but a higher lifetime risk. As individual treatment is recommended, it remains unclear whether age alone should determine the need for elective surgery. Morbidity and mortality rates of acute resection in this group are low. Prophylactic surgery may not be justified, but some long-term follow-up studies are required.

\section{Topics with consensus and high-quality evidence}

Consensus was reached on most topics with high-quality evidence. Guidelines agree on the need for imaging in addition to the clinical diagnosis, for staging and to exclude other diagnoses, preferably by CT. Symptomatic or recurrent uncomplicated disease can be treated with dietary fibre. Rifaximin and probiotics before elective surgery are considered. Mild diverticulitis can be treated in the outpatient setting if satisfactory discharge criteria are met at the time of presentation. Elective surgery is not routine treatment following any case of diverticulitis. It does not outweigh the risk of complications of recurrences, even after multiple recurrences. If elective surgery is indicated, laparoscopic surgery is preferred in experienced hands because of lower morbidity and faster recovery. For failed conservative treatment of abscesses and Hinchey III perforated diverticulitis, laparoscopic lavage is a treatment option.

\section{Suggested questions for future research}

Suggested topics for future research are summarized in Table S5. Not all those addressed in the discussion have resulted in a research question as some are already under investigation and the results are awaited. All others were debated during the ESCP $8^{\text {th }}$ Annual Meeting in a plenary session where this project was presented. Following this discussion we selected the following as the most relevant and feasible topics:

1 The need for earlier elective surgery in young and immunocompromised subgroups;

2 Treatment of abscesses following diverticulitis;

3 The risk of cancer masked by an episode of diverticulitis; and

4 Restrictive or nonrestrictive diet tolerance assessed by patient-reported outcome measurement.

We selected only four questions for future research after evaluating 23 topics. This discrepancy illustrates the amount of recent and ongoing research that is expected to provide answers to the other topics.

\section{Author contributions}

Sandra Vennix, MD, provided substantial contributions to the conception and design, acquisition of data and analysis and interpretation of data; drafted the article; and gave final approval of the version to be published. Dion G. Morton, MD, PhD, Dieter Hahnloser, MD, Johan F. Lange, MD, PhD, and Willem A. Bemelman, MD, PhD, provided substantial contributions to the conception and design, acquisition of data, or analysis and interpretation of data; revised the manuscript critically for important intellectual content; and gave final approval of the version to be published. 


\section{References}

1 Phillips B, Ball C, Sackett D et al. The Oxford Center of Evidence Based Medicine Levels of Evidence, 2009. http:// www.cebm.net/index.aspx?o=4590 (accessed June 2013).

2 Etzioni DA, Mack TM, Beart J, Kaiser AM. Diverticulitis in the United States: 1998-2005: changing patterns of disease and treatment. Ann Surg 2009; 249: 210-7.

3 Schoetz DJ Jr. Diverticular disease of the colon: a century-old problem. Dis Colon Rectum 1999; 42: 703-9.

4 Kohler L, Sauerland S, Neugebauer E. Diagnosis and treatment of diverticular disease: results of a consensus development conference. The Scientific Committee of the European Association for Endoscopic Surgery. Surg Endosc 1999; 13: 430-6.

5 Roberts P, Abel M, Rosen L et al. Practice parameters for sigmoid diverticulitis. Dis Colon Rectum 1995; 38: 125-32.

6 Sauerland S, Agresta F, Bergamaschi R et al. Laparoscopy for abdominal emergencies: evidence-based guidelines of the European Association for Endoscopic Surgery. Surg Endosc 2006; 20: 14-29.

7 Wong WD, Wexner SD, Lowry A et al. Practice parameters for the treatment of sigmoid diverticulitis-supporting documentation. The Standards Task Force. The American Society of Colon and Rectal Surgeons. Dis Colon Rectum 2000; 43: 290-7.

8 Chabok A, Pahlman L, Hjern F, Haapaniemi S, Smedh K. Randomized clinical trial of antibiotics in acute uncomplicated diverticulitis. Br J Surg 2012; 99: 532-9.

9 Charua-Guindic L, Mazza-Olmos D, Orduna-Tellez D et al. [Gastroenterology diagnosis and treatment guidelines of diverticular disease of the colon. Treatment.]. Rev Gastroenterol Mex 2008; 73: 261-4.

10 Societe Nationale Francaise de Gastroenterologie, Societe Francaise de Chirurgie Digestive. [Recommendations. Colonic diverticulosis]. [French]. Gastroenterol Clin Biol 2007; 31(8-9 Pt 2):3S5-13

11 Lledó-Matoses S. Guías clínicas de la Asociación Española de Cirujanos, Cirugía colorrectal. http://www.aecirujanos.es/publicados_por_la_AEC/guia_cirugia_colorrectal_ prologo.php (accessed June 2013).

12 Tonelli F, Di Carlo V, Liscia G, Serventi A. Diverticular disease of the colon: diagnosis and treatment. Consensus Conference, 5th National Congress of the Italian Society of Academic Surgeons. [Italian]. Ann Ital Chir 2009; 80: 3-8.

13 de Wit NJ, Berger MY, Vogelenzang R et al. [Summary of the Dutch College of General Practitioners (NHG) practice guideline on 'Diverticulitis']. Ned Tijdschr Geneeskd 2012; 156: A4140.

14 Stollman NH, Raskin JB. Diagnosis and management of diverticular disease of the colon in adults. Ad Hoc Practice Parameters Committee of the American College of Gastroenterology. Am J Gastroenterol 1999; 94: 3110-21.

15 Glasgow RE, Fingerhut A, Hunter J. SAGES Appropriateness Conference: a summary. Surg Endosc 2003; 17: 1729-34
16 Jacobs DO. Clinical practice. Diverticulitis. $N$ Engl J Med 2007; 357: 2057-66.

17 Jaffer U, Moin T. Perforated sigmoid diverticular disease: a management protocol. JSLS 2008; 12: 188-93.

18 Hammond NA, Nikolaidis P, Miller FH. Left lower-quadrant pain: guidelines from the American College of Radiology appropriateness criteria. Am Fam Physician 2010; 82: 766-70.

19 Komuta K, Yamanaka S, Okada K et al. Toward therapeutic guidelines for patients with acute right colonic diverticulitis. Am J Surg 2004; 187: 233-7.

20 Murphy T, Hunt RH, Fried M, Krabshuis JH. World Gastroenterology Organisation Practice Guidelines: Diverticular disease 2007. http://www.worldgastroenterology.org/asse ts/downloads/en/pdf/guidelines/07_diverticular_disease. pdf (accessed June 2013).

21 Korzenik JR. Diverticulitis: new frontiers for an old country: risk factors and pathogenesis. J Clin Gastroenterol 2008; 42: 1128-9.

22 Lewis M. Bleeding colonic diverticula. J Clin Gastroenterol 2008; 42: 1156-8.

23 Martel J, Raskin JB. History, incidence, and epidemiology of diverticulosis. J Clin Gastroenterol 2008; 42: 1125-7.

24 Sachar DB. Diverticulitis in immunosuppressed patients. J Clin Gastroenterol 2008; 42: 1154-5.

25 Sarma D, Longo WE. Diagnostic imaging for diverticulitis. J Clin Gastroenterol 2008; 42: 1139-41.

26 Trivedi CD, Das KM. Emerging therapies for diverticular disease of the colon. J Clin Gastroenterol 2008; 42: 1145-51.

27 West AB. The pathology of diverticulitis. J Clin Gastroenterol 2008; 42: 1137-8.

28 Rafferty J, Shellito P, Hyman NH, Buie WD. Practice parameters for sigmoid diverticulitis. Dis Colon Rectum 2006; 49: 939-44.

29 Fozard JB, Armitage NC, Schofield JB, Jones OM. ACPGBI position statement on elective resection for diverticulitis. Colorectal Dis 2011; 13(Suppl 3): 1-11.

30 Andeweg CS, Mulder IM, Felt-Bersma RJ et al. Guidelines of diagnostics and treatment of acute left-sided colonic diverticulitis. Dig Surg 2013; 30: 278-92.

31 Nederlandse Vereniging voor Heelkunde. [Guideline "Diagnosis and Treatment of Acute Colonic Diverticulitis"] Richtlijn "Diagnostiek en behandeling acute diverticulitis van het colon'. 2012, [Dutch Society of Surgery]. http:// www.heelkunde.nl/uploads/mu/22/mu22HtlbEpr-SLLyAdT5nQ/NVvH-richtlijn-Acute-diverticulitis-van-het-colon2012.pdf (accessed June 2013).

32 Andersen JC, Bundgaard L, Elbrond $\mathrm{H}$ et al. Danish national guidelines for treatment of diverticular disease. Dan Med J 2012; 59: C4453.

33 Agresta F, Ansaloni L, Baiocchi GL et al. Laparoscopic approach to acute abdomen from the Consensus Development Conference of the Societa Italiana di Chirurgia Endoscopica e nuove tecnologie (SICE), Associazione Chirurghi Ospedalieri Italiani (ACOI), Societa Italiana di Chirurgia (SIC), Societa Italiana di Chirurgia d'Urgenza e del Trauma (SICUT), Societa Italiana di Chirurgia nell'Ospedalita Priv- 
ata (SICOP), and the European Association for Endoscopic Surgery (EAES). Surg Endosc 2012; 26: 2134-64.

34 Sartelli M, Viale P, Koike K et al. WSES consensus conference: guidelines for first-line management of intra-abdominal infections. World J Emerg Surg 2011; 6: 2.

35 Hinchey EJ, Schaal PG, Richards GK. Treatment of perforated diverticular disease of the colon. Adv Surg 1978; 12: 85-109.

36 Wasvary H, Turfah F, Kadro O, Beauregard W. Same hospitalization resection for acute diverticulitis. Am Surg 1999; 65: 632-5.

37 Sher ME, Agachan F, Bortul M et al. Laparoscopic surgery for diverticulitis. Surg Endosc 1997; 11: 264-7.

38 Kaiser AM, Jiang JK, Lake JP et al. The management of complicated diverticulitis and the role of computed tomography. Am J Gastroenterol 2005; 100: 910-7.

39 Ambrosetti P, Becker C, Terrier F. Colonic diverticulitis: impact of imaging on surgical management - a prospective study of 542 patients. Eur Radiol 2002; 12: 1145-9.

40 Hansen O, Stock W. Prophylaktische Operation bei der Divertikelerkrankung des Kolons - Stufenkonzeptes durch exakte Stadieneinteilung. Langenbecks Arch Chir 1999; 384: 1257-60.

41 Andeweg CS, Knobben L, Hendriks JC, Bleichrodt RP, van Goor H. How to diagnose acute left-sided colonic diverticulitis: proposal for a clinical scoring system. Ann Surg 2011; 253: 940-6.

42 Lameris W, van Randen A, Bipat S et al. Graded compression ultrasonography and computed tomography in acute colonic diverticulitis: meta-analysis of test accuracy. Eur Radiol 2008; 18: 2498-511.

43 Lameris W, van Randen A, van Gulik TM et al. A clinical decision rule to establish the diagnosis of acute diverticulitis at the emergency department. Dis Colon Rectum 2010; 53: 896-904.

44 Toorenvliet BR, Bakker RF, Breslau PJ, Merkus JW, Hamming JF. Colonic diverticulitis: a prospective analysis of diagnostic accuracy and clinical decision-making. Colorectal Dis 2010; 12: 179-86.

45 Ambrosetti P, Jenny A, Becker C, Terrier TF, Morel P. Acute left colonic diverticulitis-compared performance of computed tomography and water-soluble contrast enema: prospective evaluation of 420 patients. Dis Colon Rectum 2000; 43: 1363-7.

46 Ambrosetti P, Grossholz M, Becker C, Terrier F, Morel P. Computed tomography in acute left colonic diverticulitis. Br J Surg 1997; 84: 532-4.

47 Liljegren G, Chabok A, Wickbom M, Smedh K, Nilsson $\mathrm{K}$. Acute colonic diverticulitis: a systematic review of diagnostic accuracy. Colorectal Dis 2007; 9: 480-8.

48 Schwerk WB, Schwarz S, Rothmund M. Sonography in acute colonic diverticulitis. A prospective study. Dis Colon Rectum 1992; 35: 1077-84.

49 Lahat A, Yanai H, Menachem Y, Avidan B, Bar-Meir S. The feasibility and risk of early colonoscopy in acute diverticulitis: a prospective controlled study. Endoscopy 2007; 39: 521-4.
50 Sakhnini E, Lahat A, Melzer E et al. Early colonoscopy in patients with acute diverticulitis: results of a prospective pilot study. Endoscopy 2004; 36: 504-7.

51 Hjern F, Jonas E, Holmstrom B et al. CT colonography versus colonoscopy in the follow-up of patients after diverticulitis - a prospective, comparative study. Clin Radiol 2007; 62: 645-50.

52 Stefansson T, Ekbom A, Sparen P, Pahlman L. Association between sigmoid diverticulitis and left-sided colon cancer: a nested, population-based, case control study. Scand J Gastroenterol 2004; 39: 743-7.

53 Aldoori WH, Giovannucci EL, Rimm EB et al. A prospective study of diet and the risk of symptomatic diverticular disease in men. Am J Clin Nutr 1994; 60: 757-64.

54 Aldoori WH, Giovannucci EL, Rimm EB et al. Prospective study of physical activity and the risk of symptomatic diverticular disease in men. Gut 1995; 36: 276-82.

55 Aldoori WH, Giovannucci EL, Rockett HR et al. A prospective study of dietary fiber types and symptomatic diverticular disease in men. J Nutr 1998; 128: 714-9.

56 Hwang SS, Cannom RR, Abbas MA, Etzioni D. Diverticulitis in transplant patients and patients on chronic corticosteroid therapy: a systematic review. Dis Colon Rectum 2010; 53: 1699-707.

57 Brodribb AJ. Treatment of symptomatic diverticular disease with a high-fibre diet. Lancet 1977; 1: 664-6.

58 Ornstein $\mathrm{MH}$, Littlewood ER, Baird IM et al. Are fibre supplements really necessary in diverticular disease of the colon? A controlled clinical trial. $\mathrm{Br} \mathrm{Med} J$ (Clin Res Ed) 1981; 282: 1353-6.

59 Tursi A, Brandimarte G, Daffina R. Long-term treatment with mesalazine and rifaximin versus rifaximin alone for patients with recurrent attacks of acute diverticulitis of colon. Dig Liver Dis 2002; 34: 510-5.

60 Bianchi M, Festa V, Moretti A et al. Meta-analysis: long-term therapy with rifaximin in the management of uncomplicated diverticular disease. Aliment Pharmacol Ther 2011; 33: 902-10.

61 Porta E, Germano A, Ferrieri A, Koch M. The natural history of diverticular disease of the colon: a role for antibiotics in preventing complications? A retrospective study. Riv Eur Sci Med Farmacol 1994; 16: 33-9.

62 Taylor I, Duthie HL. Bran tablets and diverticular disease. Br Med J 1976; 1: 988-90.

63 Biondo S, Golda T, Kreisler E et al. Outpatient versus hospitalization management for uncomplicated diverticulitis: a prospective, multicenter randomized clinical trial (DIVER trial). Ann Surg 2014; 259: 38-44.

64 de Korte N, Unlu C, Boermeester MA et al. Use of antibiotics in uncomplicated diverticulitis. Br J Surg 2011; 98: 761-7.

65 Hjern F, Josephson T, Altman D et al. Conservative treatment of acute colonic diverticulitis: are antibiotics always mandatory? Scand J Gastroenterol 2007; 42: 41-7.

66 Ridgway PF, Latif A, Shabbir J et al. Randomized controlled trial of oral vs intravenous therapy for the clinically 
diagnosed acute uncomplicated diverticulitis. Colorectal Dis 2009; 11: 941-6.

67 Brandt D, Gervaz P, Durmishi Y et al. Percutaneous CT scan-guided drainage vs. antibiotherapy alone for Hinchey II diverticulitis: a case-control study. Dis Colon Rectum 2006; 49: 1533-8.

68 Kumar RR, Kim JT, Haukoos JS et al. Factors affecting the successful management of intra-abdominal abscesses with antibiotics and the need for percutaneous drainage. Dis Colon Rectum 2006; 49: 183-9.

69 Siewert B, Tye G, Kruskal J, Sosna J, Opelka F. Impact of CT-guided drainage in the treatment of diverticular abscesses: size matters. AJR Am J Roentgenol 2006; 186: 680-6.

70 Ambrosetti P, Chautems R, Soravia C, Peiris-Waser N, Terrier F. Long-term outcome of mesocolic and pelvic diverticular abscesses of the left colon: a prospective study of 73 cases. Dis Colon Rectum 2005; 48: 787-91.

71 Ambrosetti P, Robert J, Witzig JA et al. Incidence, outcome, and proposed management of isolated abscesses complicating acute left-sided colonic diverticulitis. A prospective study of 140 patients. Dis Colon Rectum 1992; 35: 1072-6.

72 Alamili M, Gogenur I, Rosenberg J. Acute complicated diverticulitis managed by laparoscopic lavage. Dis Colon Rectum 2009; 52: 1345-9.

73 Myers E, Hurley M, O'Sullivan GC et al. Laparoscopic peritoneal lavage for generalized peritonitis due to perforated diverticulitis. Br J Surg 2008; 95: 97-101.

74 Toorenvliet BR, Swank H, Schoones JW, Hamming JF, Bemelman WA. Laparoscopic peritoneal lavage for perforated colonic diverticulitis: a systematic review. Colorectal Dis 2010; 12: 862-7.

75 Karoui M, Champault A, Pautrat K et al. Laparoscopic peritoneal lavage or primary anastomosis with defunctioning stoma for Hinchey 3 complicated diverticulitis: results of a comparative study. Dis Colon Rectum 2009; 52: 609-15.

76 O'Sullivan GC, Murphy D, O'Brien MG, Ireland A. Laparoscopic management of generalized peritonitis due to perforated colonic diverticula. Am J Surg 1996; 171: $432-4$.

77 Rogers AC, Collins D, O'Sullivan GC, Winter DC. Laparoscopic lavage for perforated diverticulitis: a population analysis. Dis Colon Rectum 2012; 55: 932-8.

78 Taylor CJ, Layani L, Ghusn MA, White SI. Perforated diverticulitis managed by laparoscopic lavage. ANZ J Surg 2006; 76: 962-5.

79 Abbas S. Resection and primary anastomosis in acute complicated diverticulitis, a systematic review of the literature. Int J Colorectal Dis 2007; 22: 351-7.

80 Salem L, Flum DR. Primary anastomosis or Hartmann's procedure for patients with diverticular peritonitis? A prospective study. Dis Colon Rectum 2004; 47: 1953-64.

81 Constantinides VA, Tekkis PP, Athanasiou T et al. Primary resection with anastomosis vs. Hartmann's procedure in nonelective surgery for acute colonic diverticulitis: a systematic review. Dis Colon Rectum 2006; 49: 966-81.
82 van de Wall BJ, Draaisma WA, Consten EC et al. DIRECT trial. Diverticulitis recurrences or continuing symptoms: operative versus conservative treatment. A multicenter randomised clinical trial. BMC Surg 2010; 10: 25.

83 Janes S, Meagher A, Frizelle FA. Elective surgery after acute diverticulitis. Br J Surg 2005; 92: 133-42.

84 Mueller MH, Glatzle J, Kasparek MS et al. Long-term outcome of conservative treatment in patients with diverticulitis of the sigmoid colon. Eur J Gastroenterol Hepatol 2005; 17: 649-54.

85 Salem L, Veenstra DL, Sullivan SD, Flum DR. The timing of elective colectomy in diverticulitis: a decision analysis. J Am Coll Surg 2004; 199: 904-12.

86 Biondo S, Pares D, Marti RJ et al. Acute colonic diverticulitis in patients under 50 years of age. Br J Surg 2002; 89: $1137-41$.

87 Guzzo J, Hyman N. Diverticulitis in young patients: is resection after a single attack always warranted? Dis Colon Rectum 2004; 47: 1187-90.

88 Hjern F, Josephson T, Altman D, Holmstrom B, Johansson C. Outcome of younger patients with acute diverticulitis. Br J Surg 2008; 95: 758-64.

89 Klarenbeek BR, Samuels M, van der Wal MA et al. Indications for elective sigmoid resection in diverticular disease. Ann Surg 2010; 251: 670-4.

90 Detry R, Jamez J, Kartheuser A et al. Acute localized diverticulitis: optimum management requires accurate staging. Int J Colorectal Dis 1992; 7: 38-42.

91 Franklin ME Jr, Dorman JP, Jacobs M, Plasencia G. Is laparoscopic surgery applicable to complicated colonic diverticular disease? Surg Endosc 1997; 11: 1021-5.

92 Solkar MH, Forshaw MJ, Sankararajah D, Stewart M, Parker MC. Colovesical fistula-is a surgical approach always justified? Colorectal Dis 2005; 7: 467-71.

93 Benn PL, Wolff BG, Ilstrup DM. Level of anastomosis and recurrent colonic diverticulitis. Am J Surg 1986; 151: 269-71.

94 Thaler K, Baig MK, Berho M et al. Determinants of recurrence after sigmoid resection for uncomplicated diverticulitis. Dis Colon Rectum 2003; 46: 385-8.

95 Gervaz P, Inan I, Perneger T, Schiffer E, Morel P. A prospective, randomized, single-blind comparison of laparoscopic versus open sigmoid colectomy for diverticulitis. Ann Surg 2010; 252: 3-8.

96 Klarenbeek BR, Veenhof AA, Bergamaschi R et al. Laparoscopic sigmoid resection for diverticulitis decreases major morbidity rates: a randomized control trial: short-term results of the Sigma trial. Ann Surg 2009; 249: 39-44.

97 Gielens MP, Mulder IM, van der Harst E et al. Preoperative staging of perforated diverticulitis by computed tomography scanning. Tech Coloproctol 2012; 16: 363-8.

98 Costi R, Cauchy F, Le BA et al. Challenging a classic myth: pneumoperitoneum associated with acute diverticulitis is not an indication for open or laparoscopic emergency surgery in hemodynamically stable patients. A 10-year experience with a nonoperative treatment. Surg Endosc 2012; 26: 2061-71. 
99 Lam TJ, Meurs-Szojda MM, Gundlach L et al. There is no increased risk for colorectal cancer and adenomas in patients with diverticulitis: a retrospective longitudinal study. Colorectal Dis 2010; 12: 1122-6.

100 Brar MS, Roxin G, Yaffe PB et al. Colonoscopy following nonoperative management of uncomplicated diverticulitis may not be warranted. Dis Colon Rectum 2013; 56: 1259-64.

101 van de Wall BJ, Draaisma WA, van Iersel JJ et al. Dietary restrictions for acute diverticulitis: evidence-based or expert opinion? Int $J$ Colorectal Dis 2013; 28: 1287-93.

102 Aldoori WH, Giovannucci EL, Rimm EB, Wing AL, Willett WC. Use of acetaminophen and nonsteroidal anti-inflammatory drugs: a prospective study and the risk of symptomatic diverticular disease in men. Arch Fam Med 1998; 7: 255-60.

103 Lorimer JW, Doumit G. Comorbidity is a major determinant of severity in acute diverticulitis. Am J Surg 2007; 193: 681-5.

104 Unlu C, de Korte N, Daniels L et al. A multicenter randomized clinical trial investigating the cost-effectiveness of treatment strategies with or without antibiotics for uncomplicated acute diverticulitis (DIABOLO trial). BMC Surg 2010; 10: 23.

105 Binda GA, Karas JR, Serventi A et al. Primary anastomosis vs nonrestorative resection for perforated diverticulitis with peritonitis: a prematurely terminated randomized controlled trial. Colorectal Dis 2012; 14: 1403-10.

106 Oberkofler CE, Rickenbacher A, Raptis DA et al. A multicenter randomized clinical trial of primary anastomosis or Hartmann's procedure for perforated left colonic diverticulitis with purulent or fecal peritonitis. Ann Surg 2012; 256: 819-26.

107 Swank HA, Vermeulen J, Lange JF et al. The ladies trial: laparoscopic peritoneal lavage or resection for purulent peritonitis and Hartmann's procedure or resection with primary anastomosis for purulent or faecal peritonitis in perforated diverticulitis (NTR2037). BMC Surg 2010; 10: 29.

108 Crowe FL, Appleby PN, Allen NE, Key TJ. Diet and risk of diverticular disease in Oxford cohort of European Prospective Investigation into Cancer and Nutrition (EPIC): prospective study of British vegetarians and non-vegetarians. BMJ 2011; 343: d4131.

109 Peery AF, Barrett PR, Park D et al. A high-fiber diet does not protect against asymptomatic diverticulosis. Gastroenterology 2012; 142: 266-72.

110 Aldoori W, Ryan-Harshman M. Preventing diverticular disease. Review of recent evidence on high-fibre diets. Can Fam Physician 2002; 48: 1632-7.

111 Parks TG, Connell AM. The outcome in 455 patients admitted for treatment of diverticular disease of the colon. Br J Surg 1970; 57: 775-8.

112 Alvarez JA, Baldonedo RF, Bear IG et al. Presentation, management and outcome of acute sigmoid diverticulitis requiring hospitalization. Dig Surg 2007; 24: 471-6.
113 Shaikh S, Krukowski ZH. Outcome of a conservative policy for managing acute sigmoid diverticulitis. Br J Surg 2007; 94: 876-9.

114 Kronborg O. Treatment of perforated sigmoid diverticulitis: a prospective randomized trial. $B r J$ Surg 1993; 80: $505-7$.

115 Zeitoun G, Laurent A, Rouffet F et al. Multicentre, randomized clinical trial of primary versus secondary sigmoid resection in generalized peritonitis complicating sigmoid diverticulitis. Br J Surg 2000; 87: 1366-74.

116 Zorcolo L, Covotta L, Carlomagno N, Bartolo DC. Safety of primary anastomosis in emergency colo-rectal surgery. Colorectal Dis 2003; 5: 262-9.

117 Biondo S, Lopez BJ, Millan M, Kreisler E, Jaurrieta E. Current status of the treatment of acute colonic diverticulitis: a systematic review. Colorectal Dis 2012; 14: el-11.

118 Herzog T, Janot M, Belyaev O et al. Complicated sigmoid diverticulitis-Hartmann's procedure or primary anastomosis? Acta Chir Belg 2011; 111: 378-83.

119 Myers E, Winter DC. Adieu to Henri Hartmann? Colorectal Dis 2010; 12: 849-50.

120 Masoomi H, Stamos MJ, Carmichael JC et al. Does primary anastomosis with diversion have any advantages over Hartmann's procedure in acute diverticulitis? Dig Surg 2012; 29: 315-20.

121 Agaba EA, Zaidi RM, Ramzy P et al. Laparoscopic Hartmann's procedure: a viable option for treatment of acutely perforated diverticultis. Surg Endosc 2009; 23: 1483-6.

122 Zdichavsky M, Granderath FA, Blumenstock G et al. Acute laparoscopic intervention for diverticular disease (AIDD): a feasible approach. Langenbecks Arch Surg 2010; 395: 41-8.

123 Chouillard E, Maggiori L, Ata T et al. Laparoscopic two-stage left colonic resection for patients with peritonitis caused by acute diverticulitis. Dis Colon Rectum 2007; 50: 1157-63.

124 Titu LV, Zafar N, Phillips SM, Greenslade GL, Dixon AR. Emergency laparoscopic surgery for complicated diverticular disease. Colorectal Dis 2009; 11: 401-4.

125 Navez B, Tassetti V, Scohy JJ et al. Laparoscopic management of acute peritonitis. Br J Surg 1998; 85: 32-6.

126 Eglinton T, Nguyen T, Raniga $S$ et al. Patterns of recurrence in patients with acute diverticulitis. Br J Surg 2010; 97: 952-7.

127 Makela JT, Kiviniemi HO, Laitinen ST. Spectrum of disease and outcome among patients with acute diverticulitis. Dig Surg 2010; 27: 190-6.

128 Bartus CM, Lipof T, Sarwar CM et al. Colovesical fistula: not a contraindication to elective laparoscopic colectomy. Dis Colon Rectum 2005; 48: 233-6.

129 Dwivedi A, Chahin F, Agrawal S et al. Laparoscopic colectomy vs. open colectomy for sigmoid diverticular disease. Dis Colon Rectum 2002; 45: 1309-14.

130 Schwandner O, Farke S, Fischer F et al. Laparoscopic colectomy for recurrent and complicated diverticulitis: a 
prospective study of 396 patients. Langenbecks Arch Surg 2004; 389: 97-103.

131 Jones OM, Stevenson AR, Clark D, Stitz RW, Lumley JW. Laparoscopic resection for diverticular disease: follow-up of 500 consecutive patients. Ann Surg 2008; 248: 1092-7.

\section{Supporting Information}

Additional Supporting Information may be found in the online version of this article:
Table S1. The Oxford Center of Evidence Based Medicine Levels of Evidence 2009 [1].

Table S2. Overview of included guidelines.

Table S3. Summary of included topics and supporting evidence.

Table S4. Overview of classifications for diverticular disease and diverticulitis.

Table S5. Topics requiring further research, based on lack of consensus or lack of evidence.

Appendix S1. Search strategies. 